\title{
Introduction to Demand-Side Factors Related to Employment of People with Disabilities
}

\author{
Fong Chan · David Strauser • Robert Gervey • \\ Eun-Jeong Lee
}

Published online: 10 June 2010

(C) Springer Science+Business Media, LLC 2010

\begin{abstract}
Introduction Demand-side employment research can play an important role in advancing the knowledge base of occupational rehabilitation. Research contributes to theory building and provides the foundation for empirically supported interventions that can improve the returnto-work success of injured workers and/or the overall labor force participation rate of people with disabilities. Methods In this article, we present our rationale for developing this special section on demand-side factors related to employment of people with chronic illness and disability. We discuss the important relationship between employer practice factors and hiring and retention of people with chronic illness and disability. We highlight in this paper some of the exciting new findings reported in the articles contained in this special section as well as some recent
\end{abstract}

F. Chan $(\bowtie)$

Department of Rehabilitation Psychology and Special Education, University of Wisconsin-Madison, 432 East Campus Mall,

Room 414, Madison, WI 53706, USA

e-mail: chan@education.wisc.edu

\section{Strauser}

Department of Kinesiology and Community Health, University of Illinois, 116 Huff Hall MC-588, 1206 South Fourth Street, Urbana-Champaign, IL 61820, USA

e-mail: strauser@ad.uiuc.edu

\section{R. Gervey}

Department of Rehabilitation Psychology and Special Education, University of Wisconsin-Madison, 432 East Campus Mall, Room 424, Madison, WI 53706, USA

e-mail: gervey@wisc.edu

\section{E.-J. Lee}

Institute of Psychology, Illinois Institute of Technology, 3105

South Dearborn, Suite 246A, Chicago, IL 60616-3793, USA

e-mail: elee20@iit.edu demand-side employment and disability research. Conclusion We intend for this special section to stimulate thinking and discussion about Incorporating demand-side strategies in vocational rehabilitation and return-to-work interventions for people with disabilities and work injuries.

Keywords Demand-side employment models . Attitudes toward disability - Disability management . Job placement . People with disabilities .

Vocational rehabilitation

\section{Introduction}

Rehabilitation researchers and scholars have consistently recognized the need to appreciate contextual and environmental factors in the development of efficacious and effective clinical practice. The World Health Organization (WHO) International Classification of Functioning, Disability, and Health (ICF) model has gained wide acceptance among international rehabilitation health researchers and professionals as a framework that can be used to support a systematic approach for understanding chronic illness and disability across cultures [1]. One of the emphases of the ICF model is related to the effect of environmental factors on full community participation of people with disabilities in all aspects of life including employment.

Participation in competitive employment and other meaningful work activities is fundamental to the physical and psychological well-being of people with and without disabilities [2]. Compared to persons who are employed, those who are unemployed tend to experience a higher prevalence of depression and anxiety disorders, use alcohol more frequently, and report lower scores on self esteem and 
quality of life measures [2]. Recognizing the importance of work, vocational rehabilitation professionals have consistently advocated for it as a fundamental human right of people with disabilities.

However, the employment rate of people with disabilities is notoriously low; about $35 \%$ of working-age people with disabilities are employed comparing to $78 \%$ of those without disabilities [3]. Importantly, two-thirds of the unemployed persons with chronic illness and disability indicated that they would like to work but could not find jobs. The unemployment and under employment problem among people with disabilities has been made more acute due to the recent financial crisis. This recession has a disproportionate impact on workers with disabilities, with the number of employed workers with disabilities declined at a rate more than three times that of workers without disabilities, and the unemployment rate rose dramatically to levels exceeding that of other workers [4].

Clearly, the traditional supply-side approach of providing medical, psychological, educational, and vocational services to improve functioning, stamina, and job skills alone without taking into account of organizational behaviors, employer needs, and the changing labor economy is no longer adequate for achieving meaningful employment outcomes for people with disabilities. This is because supply-side employment models ignore variables related to employer demand (and the interaction of employer demand and the environment) as predictors of employment outcomes for people with disabilities. As such, the need to consider demand-side behaviors and how these employer practice factors interact with personal factors to affect job placement of people with disabilities and return-to-work success of injured workers is increasingly becoming an important research topic in occupational rehabilitation. For example, employment demand is changing and projected to shift due to fundamental structural economic changes [5]. Demand-side employment research can help identify the largest or fastest growth areas of employment opportunities and the skill sets needed for these demand occupations. Employers are less risk averse in occupations where the demand is high and the supply of qualified workers is low. Preparing people with disabilities for these occupations will increase their chance of being hired. The organizational structures of American companies are also changing. The organizational chart is now flatter and team-based and the emphasis is on flexibility, productivity, and workplace socialization skills. Therefore, rehabilitation professionals must have a thorough understanding of the real concerns of employers about hiring and retention of persons with disabilities and be able to address their concerns and needs. Helping people with disabilities develop flexible, versatile, and adaptable work skills to meet employer expectations and requirements for jobs in the new economy will improve their odds of obtaining employment.

The U.S. Department of Labor-The Office of Disability Employment Policy (DOL-ODEP) conducted a study with employers in 13 major metropolitan areas representing variety of industries, company sizes and both for-profit and not-for-profit organizations to ask employers what they consider as the most important issue affecting the poor hiring and job retention climate for people with disabilities [6]. The most common answer given was that employers need more accurate and practical information to dispel preconceptions and concerns about hiring and retaining people with disabilities. DOL-ODEP conducted a largescale survey as a follow-up to their focus group study in 2008 [7] to examine employer perspectives on the employment of people with disabilities. The nature of the work cannot be effectively performed by a person with a disability is cited as a hiring challenge for hiring people with disabilities by 72.6 percent of all companies. Additionally, health care costs, workers compensation costs, and fear of litigation are cited as major challenges by small and medium companies. Strauser and Chan [8] conducted three focus group studies with employers in Chicago and Milwaukee. The focus group participants identified many positive attributes and good reasons for hiring people with disabilities. However, negative attitudes of co-workers or supervisors and the lack of supply of "qualified" workers with disabilities are cited as major barriers to hiring and retaining people with disabilities by participants in their study. Misperceptions that are still held by many employees identified by Strauser and Chan [8] include:

- People with disabilities often require extra time to learn new work tasks.

- People with disabilities often require some sort of job accommodations (e.g., specialized equipment, facility modifications, adjustments to work schedules or job duties) to do their job.

- People with disabilities have trouble getting their work done on time and often needs others to help them finish the job.

- Co-workers are not very comfortable working with people with disabilities.

- People with disabilities tend to call in sick more often than other workers due to health or personal problems.

- People with disabilities have trouble getting along with others on the job.

Both the DOL studies [6, 7] and the Strauser and Chan study [8] concluded that before demand-side employment can become truly effective, research into employer perceptions and attitudes toward hiring and retaining persons with disabilities is needed to complement current demandside employment research. To promote demand-side 
research in occupational rehabilitation, we have invited six demand-side employment research groups to contribute to this special section of the Journal of Occupational Rehabilitation on demand-side factors related to employment of people with disabilities. Collectively, these studies represented the perspectives of 759 human resources and line managers on employment of people with disabilities.

Specifically, in this special section, Copeland, Chan, Bezyak, and Fraser [9] validated the factorial structure of the Affective Reactions subscale of the Disability Questionnaire to assess employers' attitudes toward individuals with disabilities. They found that the Affective Reactions subscale has three underlying dimensions: (1) negative perceptions, (2) willingness to accommodate, and (3) equal treatment. Copeland et al. found that previous experience working with people with disabilities is associated with attitudes toward disability and positive attitudes toward people with disabilities are associated with positive beliefs about the reasonableness of accommodating people with disabilities in the workplace. They concluded that the Affective Reaction scale can be used to measure employer attitudes toward people with disabilities in demand-side employment research. Similarly, Amir et al. [10] conducted a study to survey line managers' attitudes toward return to work after cancer in the United Kingdom. They found that line managers' attitudes can be assessed using five attitude dimensions: (1) fearful attitudes towards cancer survivors, (2) supportive attitudes, (3) perceived burden, (4) maintaining normality, and (5) financial benefits issues. Amir et al. found that line managers generally hold positive attitudes about providing workplace support to help cancer survivors return to work. However, line manager's positive attitudes toward workplace support are countered by their concerns about individual cancer survivors' ability to engage in work related activities, meeting the demands of employment. Both Copeland et al.'s study and Amir et al.'s research support the effect of positive contact experience with people with disabilities in social situation and in the workplace. Their research also supports the importance of contact, education, workplace support, and effective communication between managers and individuals with disabilities in the workplace.

Habeck et al. [11] and Chan et al. [12] focused their demand-side research on organizational behaviors and company policies. Habeck et al. [11] surveyed 95 members of the Disability Management Employer Coalition to examine absence and disability management (ADM) and retention polices and practices and their effectiveness as well as how these employer practices influence hiring of people with disabilities. They found that ADM practice was related to improving health and managing health conditions and resolving disability and return to work issues. Their finding substantiated a positive relationship between ADM policies and retention of existing employees with work-injuries or health problems. However, retention of employees with health or injury problems and ADM policies and practices were not found to make any difference when it came to hiring potential [new] employees with disabilities. In fact, only disability attitudes of the company (e.g., inclusion of disability in diversity plan) were found to be significantly associated with hiring new employees with disabilities. Effective retention and ADM policies and practices are not related to hiring of prospective employees with disabilities.

Chan et al. surveyed 132 human resources (HR) managers and line managers in the Midwest region of the United States to examine demand-side employment factors that may influence hiring and retention of people with physical disabilities. They found that corporations have not been providing or emphasizing Americans with Disabilities Act (ADA) training for their managers as when the ADA was first passed in 1990. The HR and line managers in their study rated themselves as having moderately positive attitudes toward hiring and retention of workers with disabilities. However, they reported ambivalence about people with disabilities as productive and reliable workers. They also identified challenges related to hiring and supporting employees with disabilities including lack of resources, incentives, and knowledge of ADA and reasonable accommodations. Managers in the Chan et al.'s study also indicated a stronger emphasis of gender and race and not disability as the diversity focus of their companies. However, in their regression analysis, Chan et al. found that knowledge of ADA and job accommodation and inclusion of disability in diversity efforts were significantly associated with commitment of the company to hire people with disabilities. They recommended that rehabilitation professionals offer training and technical assistance in ADA and workplace accommodations for manager level employees. They also recommended that rehabilitation professionals use a demand-side model for job placement to carefully screen and match highly qualified individuals with disabilities to demand occupations that need to be filled. Finally, they recommended that rehabilitation professionals devote more time and effort to developing targeted intervention to help modify the attitudes of $\mathrm{HR}$ and hiring managers and the diversity policies of companies so that they are more inclusive of persons with disabilities.

Fraser et al. [13] cogently pointed out that the unemployment and underemployment problem of people with disabilities cannot be addressed by changing employer attitudes alone. As supported by the articles published in this special section, employers generally hold moderately positive attitudes toward people with disabilities and express a willingness to hire and retain workers with disabilities. However, there is a huge gap between intention to 
hire and actual hiring and retention behaviors. For example, only $19.1 \%$ of the employers surveyed in the 2008 DOL ODEP study reported employing people with disabilities. As suggested by McMahon [14], this $19.1 \%$ figure must be interpreted in the twenty-first century context; if so few employers report employing women and minorities in their workforce today, there would be an outcry in the public about this injustice.

Fraser et al. [13] identified Ajzen and Fishbein's Theory of Planned Behavior [15] as holding promise for helping to bridge employer behavior intention with actual hiring and retention behaviors. They conducted a series of three semi-structured focus groups with Human Resources directors, chief operating officers (COOs), or chief executive officers (CEOs) of small, medium, and large Seattle area companies and analyzed the qualitative data using Theory of Planned Behavior as the conceptual framework. They analyzed data for central themes based on the three key components of intention (i.e., attitudes/behavior beliefs of employers, subjective norms/normative beliefs, and control beliefs). They found that many employers of small- and mid-sized companies still believe that people with disabilities can not do the work or are somehow less qualified whereas for large companies, the challenge is to convince departmental and team managers that outreaching workers with disabilities would be a worthwhile hiring practice. They concluded normative beliefs contributed significantly to intention to hire people with disabilities and therefore intervention at the key decision-maker level is the most important first step in demand-side employment intervention. However, changing mid-level managers' perceptions/attitudes about people with disabilities is also important.

Finally, Bjelland et al. [16] argued that older workers and workers with disabilities are underutilized groups that can help employers address the worker shortage challenge expected as a result of the changing demographics and evolving workforce. They analyzed the U.S. Equal Employment Opportunity Commission (EEOC) Employment Discrimination Charge Data to examine perceived age and disability discrimination and their intersection to help employers better understand age and disability discrimination issues. Bjelland et al. [16] found that employment discrimination claims that originate from older or disabled workers are concentrated within a subset of issues that include reasonable accommodation, retaliation, and termination. They also found that small firms are most vulnerable for age and disability discrimination. The Bjelland et al. [16] study underscored the importance of understanding employer hiring and retention behavior from the perspective of the Americans with Disabilities Act. Thus, these authors suggest that demand-side employment models must offer technical assistance and training to employers in the areas of ADA consultation and workplace accommodations.

In summary, we are pleased to introduce this special section of the Journal of Occupational Rehabilitation devoted to demand-side employment and disability research. The articles submitted for this special section have been prepared to provide readers with theoretical concepts, analytic strategies, and empirical findings on employers' perspective on hiring and retention of people with disabilities. The findings of these studies also provide recommendations for developing demand-side employment strategies and interventions that can improve employment outcomes of people with disabilities. These studies will hopefully stimulate thinking and facilitate discussions about the potential integration of demand-side employment models in occupational rehabilitation. We hope that Journal of Occupational Rehabilitation readers will find this special section to be an important and useful resource, stimulating the next generation of demand-side employment research in occupational rehabilitation. Finally, we would like to thank Michael Feuerstein, Editor and Patricia A. Findley, Managing Editor of the Journal of Occupational Rehabilitation for the opportunity to present this special section. Their patience, support, and advice are truly deeply appreciated.

Acknowledgments Preparation of this special section was supported through the Virginia Commonwealth University's Coordination, Outreach and Research Center (CORC) for the National Network of Americans with Disabilities Act (ADA) Resource Centers, National Institute on Disability and Rehabilitation Research, U.S. Department of Education (PR\# H133A060087).

\section{References}

1. Bruyère $S$, VanLooy $S$, Peterson $D$. The international classification of functioning, disability and health (ICF): contemporary literature overview. Rehabil Psychol. 2005;50:113-21.

2. Dutta A, Gervey R, Chan F, Chou CC, Ditchman N. Vocational rehabilitation services and employment outcomes of people with disabilities: a United States study. J Occup Rehabil. 2008; $18: 326-34$.

3. National Organization on Disability Report. Empowerment for Americans with disabilities: breaking barriers to careers and full employment. Washington, DC: Author; 2003.

4. Kaye, SH. The disproportionate impact of the great recession on workers with disabilities. Institute for Health and Aging, University of California: San Francisco. Available at: http://www. disabilityfunders.org/webfm_send/111.

5. Gilbride DD, Stensrud R. Demand-side job development: a model for the 1990s. J Rehabil. (1992);58(4):34-9.

6. Grizzard WR. Meeting demand-side expectations and needs. A presentation at the ADA 15th Anniversary Seminar, Washington, DC; July, 2005.

7. Domzal C, Houtenville A, Sharma R. Survey of employer perspectives on the employment of people with disabilities: technical report. (Prepared under contract to the Office of Disability and 
Employment Policy, U.S. Department of Labor). McLean, VA: CESSI; 2008.

8. Chan F, Strauser D. Demand side employment factors affecting job placement and job retention among people with disabilities. Paper presented at the cancer survivorship and work seminar. London: Goldsmith College; 2007.

9. Copeland J, Chan F, Bezyak J, Fraser RT. Assessing cognitive and affective reactions of employers toward people with disabilities in the workplace. J Occup Rehabil. doi:10.1007/ s10926-009-9207-y.

10. Amir Z, Wynn P, Chan F, Strauser D, Whitaker S, Luker K. Return to work after cancer in the UK: attitudes and experiences of line managers. J Occup Rehabil. doi:10.1007/s10926-0099197-9.

11. Habeck R, Hunt A, Rachel CH, Kregel J, Chan F. Employee retention and integrated disability management practices as demand side factors. J Occup Rehabil. doi:10.1007/s10926-0099225-9.
12. Chan F, Strauser D, Maher P, Lee EJ, Jones R, Johnson ET. Demand-side factors related to employment of people with disabilities: a survey of employers in the Midwest region of the United States. J Occup Rehabil; (in press).

13. Fraser RT, Johnson K, Hebert J, Ajzen I, Copeland J, Brown P, Chan F. Understanding employers' hiring intentions in relation to qualified workers with disabilities: preliminary findings. J Occup Rehabil. doi:10.1007/s10926-009-9220-1.

14. McMahon BT. Facts are stubborn things: employment and disability in the new century-ADA and ADA Amendments of 2008 [Video]. Madison, WI: Department of Rehabilitation Psychology and Special Education, University of Wisconsin; 2008.

15. Fishbein M, Ajzen I. Predicting and changing behavior: the reasoned action approach. New York: Psychology Press; 2010.

16. Bjelland MJ, Bruyère SM, Schrader SV, Houtenville AJ, RuizQuintanilla A, Webber DA. Age and disability employment discrimination: Occupational rehabilitation Implications. J Occup Rehabil. doi:10.1007/s10926-009-9194-z. 